\title{
PESQUISA ETNOGRÁFICA: INICIANDO SUA COMPREENSÃO
}

\author{
Cristina Maria Garcia de Lima * \\ Giselle Dupas ** \\ Irma de Oliveira *** \\ Seiko Kakehashi ***
}

LIMA, C.M.G. de; DUPAS, G.; OLIVEIRA, I.de; KAKEHASHI, S. Pesquisa etnográfica: iniciando sua compreensão. Rev. latino-am.enfermagem, Ribeirão Preto, v. 4, n. 1, p. 21-30, janeiro 1996.

O presente estudo visa apresentar algumas considerações teóricas sobre a pesquisa etnográfica com o propósito de divulgar este tipo de investigação para a enfermagem. O texto apresenta definição de alguns autores, bem como aspectos metodológicos desta abordagem.

UNITERMOS: pesquisa, pesquisa etnográfica, etnografia

\section{INTRODUÇÃO}

Nosso interesse pela pesquisa etnográfica surgiu enquanto cursávamos a disciplina Teoria de Conhecimento, no curso de pós-graduação, que possibilitou o nosso contacto com várias abordagens metodológicas que podem ser utilizadas na realização de pesquisas nas diversas áreas de enfermagem.

\footnotetext{
* Mestre em Enfermagem, Professor Assistente da Faculdade de Medicina de Botucatu - UNESP _ Curso de Enfermagem

** Mestre em Enfermagem, Professor Assistente do Departamento de Enfermagem e Obstetrícia da Universidade Federal de São Carlos

*** Mestre em Enfermagem Pediátrica e Pediatria Social, Professor Assistente do Departamento de Enfermagem da Faculdade de Ciências Médicas da UNICAMP
} 
Ao estudarmos a pesquisa qualitativa deparamo-nos com a etnografia e percebemos que a sua aplicação à enfermagem poderia representar uma nova forma de cuidar, que leva em conta as necessidades do cliente/paciente sob o prisma do seu grupo cultural e que, a nosso ver, pode revelar novas dimensões para a prática da profissão.

Assim, propomos realizar este estudo que, na verdade, trata-se de um exercício de reflexão sobre a etnografia, tecendo algumas considerações teóricas que visam contribuir para a sua divulgação, bem como para sua aplicação na enfermagem.

\section{PESQUISA ETNOGRÁFICA}

\subsection{Considerações Gerais}

Dentre as abordagens metodológicas na pesquisa qualitativa etnometodologia tem suas raízes plantadas na fenomenologia, com marcas do interacionismo simbólico e da sociologia weberiana. O senso comum é valorizado para a compreensão do social e o observador procura interpretar aquilo que o sujeito já havia interpretado dentro do seu universo simbólico. É um estudo de significado da "vida diária". É uma postura/posição metodológica que se opõe aos modos tradicionais de manipular os problemas de ordem social (essência vista "de fora"), colocando que ela se cria na própria interação, sendo uma forma nova de apreender a realidade, sabendo que nenhuma delas consegue apreendê-la totalmente (BRAGA, 1988).

Segundo esta mesma autora, no processo de investigação, deve-se levar em consideração não só o que é visto e experimentado, como também o não explicitado, aquilo que é dado por suposto, ou seja, de uma colocação geral, supostamente entendida, vai se subtraindo questionamentos, até que tudo fique explícito. A linguagem é um ponto importante a se considerar, pois somente o autor da sentença pode dar a dimensão exata, o conteúdo e as razões de suas colocações, já que são as experiências que definem o conteúdo significativo da sentença.

Para MINAYO (1992), a etnometodologia compreende o conjunto de reflexões que se abrigam sob seu próprio nome, além do interacionismo simbólico, da história de vida e da história oral. Seu berço foi a Universidade de Chicago e seu principal teórico Roberto Park, que já nas décadas de 20 e 30 preconizava a experiência direta com atores sociais para a compreensão de sua realidade.

As realidades sociais, quando estudadas sob a ótica de um sistema considerado padrão, são distorcidas, não levando em consideração as culturas de grupos na construção dos significados. Enquanto a etnologia estuda o significado 
da vida diária, a etnografia procura descrever esses significados (BRAGA, 1988).

O método etnográfico tem a finalidade de desvendar a realidade através de uma perspectiva cultural (SEGOVIA HERRERA, 1988).

Para BERNARDI (1974) são quatro os fatores essenciais da cultura: "o anthropos, ou seja, o homem na sua realidade individual e pessoal; o ethnos, comunidade ou povo entendido como associação estruturada de indivíduos; o oikos, o ambiente natural e cósmico dentro do qual o homem se encontra a atuar; o chronos, o tempo, condição ao longo do qual, em continuidade de sucessão, se desenvolve a atividade humana". Acrescenta que um fator por si só não constitui a cultura, mas a ação dos quatro fatores é uma constante no processo cultural. Cada ação do indivíduo único, mesmo sendo novo, original ou importante, estaria destinada a perder-se ou apagar-se se não fosse apropriada pela coletividade, articulada num conjunto orgânico e transmitida como parte do patrimônio comum.

No entanto, a coletividade (grupo social) segundo LEACH (1982, p. 41), não é do ponto de vista sociológico culturalmente homogênea. Quase todas as sociedades empíricas estratificadas em classes sociais, em castas hereditárias e em hierarquia de classes, e cada estrato do sistema é marcado com o seu próprio atributo cultural - usos lingüísticos, métodos, estilos de vestuário, alimentação, habitação etc.

MALINOWSKI (1953) considera a cultura como um todo integrado ou global do qual os elementos culturais singulares são as partes constitutivas. Só a análise funcional está à altura de descobrir e de compreender os significados dos elementos culturais individuais, porque os vê nas suas relações com o todo da cultura. O reflexo da totalidade do fenômeno cultural sobre os aspectos elementares e normais do viver humano, era evidenciado pelo autor. Em sua visão de pesquisador, considerou o evoluir dinâmico da realidade em correspondência com a condição humana - "... a realidade não é um esquema lógico coerente, mas antes, uma mistura em ebulição de princípios em conflito".

O autor salienta que, para a apreensão da realidade, o trabalho de campo é condição sine qua non, o que fez dele o mestre do método antropológico da observação participante.

O trabalho de campo, segundo HERSKOVITS (1963), consiste em dirigir-se ao povo que se pretende estudar, escutar as conversas, visitar os lares, assistir aos ritos, observar o comportamento habitual, interrogar sobre as tradições para obter, mediante o conhecimento direto dos modos de vida, uma visão de conjunto da cultura ou analisar algum especial da mesma. Os dados obtidos lançarão luz sobre os problemas essenciais da natureza e funcionamento da cultura e do comportamento social humano. Somente uma ampla base de dados descritivos será capaz de fornecer a primazia da cultura na modelagem da conduta.

No que diz respeito à pratica de enfermagem, é necessário conhecer a cultura e a conduta, e os modos pelos quais estas influenciam o processo saúdedoença. 
Cabe destacar que, nesta modalidade de investigação, observação, descrição e análise das tradições da população que está sendo estudada, são passos essenciais para sua compreensão. Por outro lado, julgamento, avaliação e ou configuração das condutas observadas mão fazem parte desta metodologia. Conseqüentemente, o êxito deste tipo de investigação depende em grande parte da sensibilidade do pesquisador diante das situações com as quais se depara e da interação que estabelece com a população em estudo. Através do "tato conquistará o respeito e a confiança das pessoas e definitivamente seus materiais serão mais ricos", HERSKOVITS (1963, p. 104).

Segundo SPRADLEY (1979), etnografia "é a descrição de um sistema de significados culturais de um determinado grupo", objetivando entender um outro modo de vida, mas do ponto de vista do informante. O trabalho de campo, então, inclui o estudo disciplinado do que o mundo é, como as pessoas têm aprendido a ver, ouvir, falar, pensar e agir de formas diferentes. Mais do que um estudo sobre as pessoas, etnografia significa "aprendendo com as pessoas".

O mesmo autor cita MALINOWSKY (1922, p. 25) que define a etnografia com a "compreensão do ponto de vista do outro, sua relação com a vida, bem como a sua visão do mundo".

SEGOVIA HERRERA (1988) e LÜDKE \& ANDRÉ (1986) citam Wilson (1977), para quem a pesquisa etnográfica fundamenta-se em dois conjuntos de hipóteses sobre o comportamento humano:

- a hipótese naturalista-ecológica, que afirma ser o comportamento humano significativamente influenciado pelo contexto em que se situa, daí a necessidade de estudar o indivíduo em seu ambiente natural;

- a hipótese qualitativo-fenomenológica, que determina ser quase impossível entender o comportamento humano sem tentar entender o quadro referencial dentro do qual os indivíduos interpretam seus pensamentos, sentimentos e ações. Desta forma, o pesquisador deve exercer o papel subjetivo de participante e o papel objetivo de observador, a fim de compreender e explicar o comportamento humano.

Para SEGOVIA HERRERA (1988) etnografia é a descrição de uma cultura particular que possibilita a descoberta de domínios de conhecimentos, bem como a interpretação de comportamento dos elementos culturais em relação a determinados aspectos.

LEININGER (1985, p.35), define etnografia como um processo sistemático de observar, detalhar, descrever, documentar e analisar o estilo de vida ou padrões específicos de uma cultura ou subcultura, para apreender o seu modo de viver no seu ambiente natural.

\subsection{Metodologia}

Para verificar se um estudo pode ser chamado de etnográfico, "basta 
verificar se a pessoa que lê esse estudo consegue interpretar aquilo que ocorre no grupo estudado tão apropriadamente como se fosse um membro deste grupo" (Wolcott, 1975, apud LÜDKE ANDRÉ, 1986).

Os mesmos autores apresentam ainda os critérios para utilização da abordagem etnográfica propostos por Wolcott e resumidos por Firestone e Dowson (1981) :

1) o problema é redescoberto no campo e, assim, o etnógrafo deve evitar definições rígidas e apriorística de hipótese, pois, ao mergulhar na situação, o problema inicial da pesquisa deverá ser revisto e aprimorado;

2) o pesquisador deve realizar a maior parte do trabalho de campo pessoalmente, pois a experiência direta com a situação em estudo permite um contato íntimo e pessoal com a realidade estudada;

3) o trabalho de campo deve permitir uma longa imersão na realidade para entender as regras, costumes e convenções que governam a vida do grupo estudado;

4) o pesquisador deve ter tido uma experiência com outros povos de outras culturas, pois o contraste com outras culturas ajuda a entender melhor 0 sentido que o grupo estudado atribui às suas experiências;

5) a abordagem etnográfica combina vários métodos de coleta, sendo que os principais são: observação participante e entrevista com informantes. Entretanto, além destes, outros métodos podem ser usados, como os levantamentos, as histórias de vida, a análise de documentos, testes psicológicos, videotypes, fotografias e outros;

6) o relatório etnográfico apresenta uma grande quantidade de dados primários, que permitem, além de descrições precisas da situação estudada, ilustrar a perspectiva dos participantes, isto é, a suas maneira de ver o mundo e a suas próprias ações.

As autoras LÜDKE \& ANDRÉ (1986), prosseguem descrevendo três etapas para a realização da pesquisa etnográfica:

1) Exploração - envolve a seleção e definição de problemas, a escolha do local onde será feito o estudo e o estabelecimento de contatos para a entrada no campo. Nesta fase, são realizadas as primeiras observações com a finalidade de adquirir maior conhecimento sobre o fenômeno e possibilitar a seleção de aspectos que serão mais sistematicamente investigados. Essas primeiras indagações orientam o processo da coleta de informações e permitem formulação de uma série de hipóteses que podem ser modificadas à medida que novos dados vão sendo coletados.

2) Decisão - consiste numa busca mais sistemática daqueles dados que 0 pesquisador selecionou como os mais importantes para compreender e interpretar o fenômeno estudado. Assim, os autores, citando Wilson (1977), afirmam que os tipos de dados relevantes são: forma e conteúdo da interação verbal dos participantes; forma e conteúdo da interação verbal com o pesquisador; comportamento nãoverbal; padrões de ação e não-ação; traços, registros de arquivos e documentos. Os 
tipos de dados coletados podem mudar durante a investigação, pois as informações colhidas e as teorias emergentes devem ser usadas para dirigir a subseqüente coleta de dados.

3) Descoberta - consiste na explicação da realidade; isto é, na tentativa de encontrar os princípios subjacentes ao fenômeno estudado e de situar as várias descobertas num contexto mais amplo. Deve haver uma interação contínua entre os dados reais e as suas possíveis explicações teóricas permitindo estruturação de um quadro teórico, dentro do qual o fenômeno pode ser interpretado e compreendido.

SPRADLEY (1979) coloca que a análise etnográfica envolve uma busca das partes de uma cultura, a relação entre essas partes e a relação das partes com o todo; e apresenta quatro tipos de análise: de domínios, taxonômica, componencial e de temas, todas incluídas na seqüência para o desenvolvimento da pesquisa. O primeiro nível de análise de domínios inicia-se a partir das anotações gerais obtidas das observações e questionamentos. Um domínio representa uma categoria simbólica do significado cultural que inclui categorias menores.

A estrutura do domínio é constituída de três elementos básicos:

- termos incluídos ou nomes para as categorias menores;

- termos cobertos ou nome para o domínio;

- relação semântica entre os termos inclui o termo cultural.

As relações semânticas operam pelo princípio geral de inclusão. A sua função é definir "termos incluídos" e situá-los dentro de um domínio cultural.

$\mathrm{Na}$ análise de domínios pode-se começar por identificar os "termos encobertos", os "termos incluídos" ou as relações semânticas. Quando se encontra uma parte do domínio, esta pode ser usada para novas descobertas. Estes domínios são identificados como:

- domínios populares: a descrição é feita na linguagem das pessoas;

- domínios mistos: utiliza parte das palavras dos informantes e um termo analítico é selecionado para completar o domínio;

- domínios analíticos: quando muitos dos significados culturais permanecem tácitos e se infere sobre o que as pessoas fazem, dizem, e os instrumentos que elas usam.

$\mathrm{Na}$ construção das taxonomias, os dados que vêm dos informantes são organizados numa hierarquia. A taxonomia tem a finalidade de conduzir a análise em profundidade e demonstrar a organização interna de um domínio.

O terceiro nível de análise, a componencial, representa uma busca sistematizada de atributos ou componentes do significado (que são nos contrastes). A partir desta análise são elaboradas questões para que os resultados sejam, validados.

$\mathrm{Na}$ análise dos temas, as conceituações que ligam os domínios oferecem uma visão holística da cultura em estudo; e a referência de uma idéia em mais de um domínio sugere a possibilidade de se tratar de um tema cultural. 
Transportando os princípios gerais da etnografia para a enfermagem, LEININGER (1985) desenvolveu um método de pesquisa que denominou de etnoenfermagem e apresentou uma forma de análise que compreende:

- coleta e documentação de dados brutos: esta fase inclui registro de dados de informantes obtidos a partir de observações, entrevistas e experiências de participação.

- identificação de descrições de componentes: os dados são classificados de forma a permitir a compreensão da situação ou questões em estudo;

- análise contextual e de padrões: busca-se a saturação, consistência e credibilidade dos dados;

- temas, achados relevantes e formulações teóricas: é a fase mais refinada de análise e síntese dos dados. Requer síntese de reflexões, elaboração de modelo e análise criativa de dados. O pesquisador abstrai os temas e pode elaborar formulações teóricas e recomendações.

Segundo KENDALL (1984), o conhecimento das informações culturais de uma determinada comunidade fornece subsídios valiosos para projetos de ação em assistência primária.

O papel da pesquisa etnográfica está sendo cada vez mais reconhecido em razão do que ela representa para o desenvolvimento de programas de assistência e de ensino para comunidades, já que apresenta a fonte de informação cultural (BENTLEY, 1988; AMADOR, 1991; GUALDA, 1993; SEGOVIA HERRERA, 1988; ROSENTHAL, 1989).

\section{CONSIDERAÇÕES FINAIS}

Os diferentes métodos de pesquisa são necessários e importantes para atender e possibilitar a realização de investigações em diversas áreas do conhecimento. Os métodos não competem entre si, mas a natureza do estudo é que determina qual é o método mais indicado (ROSENTHAL, 1989).

A breve revisão da etnografia em enfermagem demonstrou que esta modalidade de investigação tem sido utilizada pelos enfermeiros norte americanos desde a década de oitenta (LEININGER, 1985; ROSENTHAL, 1989).

Outro ponto importante a destacar é que a etnografia é uma metodologia propícia para descobrir a maneira de viver e as experiências das pessoas - a sua visão do mundo, os sentimentos, ritos, padrões, significados, atitudes, comportamentos e ações. Esta perspectiva permite apreender o fenômeno humano na sua totalidade. Assim sendo, a compreensão dos fenômenos, eventos e situações de enfermagem que apresentam características de ações em desenvolvimento 
(saúde, bem estar, o processo de cuidar, o processo de trabalho em enfermagem, o processo de ensino-aprendizagem) constituem objeto de estudo apropriado nesta abordagem.

$\mathrm{Na}$ enfermagem brasileira, estudos etnográficos parecem ser incipientes por esta se encontrar presa ao desenvolvimento de pesquisas, com métodos quantitativos ou tradicionais.

Entretanto, a interação enfermeiro/paciente, as relações na equipe de enfermagem de saúde vêm despertando o interesse do enfermeiro pela pesquisa qualitativa e, dentre elas, a etnografia, que possibilita novos conhecimentos do homem na sua experiência com saúde e doença, as suas expectativas relacionadas a etapas da vida e de suas crenças ao tratamento. A compreensão de tais aspectos, será um instrumento definitivo e desafiador para que a enfermagem possa modificar a sua forma de cuidar, que está voltada a rotinas e protocolos de assistência das instituições e que, muitas vezes, ignora e desconhece as reais necessidades do receptor do cuidado, uma vez que o outro é visto de forma descontextualizada do seu ambiente/sistema cultural.

Por estas razões, a etnografia nos aponta um caminho que precisa ser melhor explorado, para que possamos dar sentido às intervenções de enfermagem.

\section{ETHNOGRAPHIC RESEARCH: BEGINNING TO COMPREHEND IT}

This study aimed at presenting a number of theoretical considerations related to ethnographic investigation viewing the disclosing of that type of nursing research. This study shows the definitions provided by various authors is addition to the methodology aspects regarding this type of approach.

UNITERMS: research, ethnographic research, ethnography

\section{INVESTIGACIÓN ETNOGRÁFICA: INICIANDO SU COMPRENSIÓN}

Este estudio presenta algunas consideraciones teóricas sobre la investigación etnográfica, con el propósito de divulgar este tipo de investigación para enfermería. El 
texto contempla la definición de algunos autores, así como los aspectos metodológicos de este abordaje.

UNITERMOS: investigación, investigación etnográfica, etnografía

\section{REFERÊNCIAS BIBLIOGRÁFICAS}

01. AMADOR, M.V.P. Educação em enfermagem: uma análise etnográfica da colaboração serviços/escolas nos estágios clínicos. São Paulo, 1991. p. 330. Tese (Doutorado) - Escola de Enfermagem, Universidade de São Paulo.

02. BENTLEY, M.E. et al. Rapid ethnographic assessment: applications in a diarrhea management program. Soc. Sci. Med., v. 27, n. 1, p. 107-16, 1988.

03. BERNARDI, B. Introdução aos estudos etno-antropologicos: perspectivas do homem. São Paulo: Edições 70, 1974. p.50-61.

04. BOWERS, L. Ethno methodology I: an approach to nursing research. Int. J. Nurs. Stud., v. 29, n. 1, p. 59-69, 1992.

05. BRAGA, C.M.L. A etnometodologia como recurso metodológico na análise sociológica. Ci. Cult., v.40, n.10, p.957-66, out., 1988.

06. GUALDA, D.M.R. Eu conheço minha natureza: um estudo etnográfico da vivência do parto. São Paulo, 1992. p. 185. Tese (Doutorado) - Escola de Enfermagem, Universidade de São Paulo.

07. HERSKOVITS, M.J. Antropologia cultural: o homem e seu trabalho. São Paulo: Mestre Jou, 1963. p. 98-108.

08. KENDALL, C. et al. Ethnomedicine and oral rehydration therapy: a case of study of ethnomedical investigation and program planning. Soc. Sci. Med., v.19, n.3, p. 253-60, 1984.

09. LEACH, E. A diversidade da antropologia: perspectivas do homem. Lisboa: Edições 70, 1982.

10. LEININGER, M. Qualitative research methods in nursing. Orlando: Grune \& Stratton, 1985. cap. 3, p. 33-71: Ethnography and ethnonursing models and modes of qualitative dada analysis.

11. MALINOWSKY, B. Sex and repression in a savage society. London: Routledge e Kegon, 1953.

12. MINAYO, M.C.S. O desafio do conhecimento. São Paulo/Rio de Janeiro: Hucitec/Abrasco, 1992.

13. ROSENTHAL, T. T. Using ethnography to study nursing education. West.J.Nurs.Res., v. 11, n. 1, p. 115-27, 1989. 
14. SEGOVIA HERRERA, M. Risco e segurança do trabalho desde o ponto de vista de um grupo de trabalhadores de uma agência de distribuição de energia elétrica. In: ENCONTRO INTERAMERICANO DE PESQUISA QUALITATIVA EM ENFERMAGEM, I. São Paulo. Trabalhos. São Paulo, Escola de Enfermagem da Universidade de São Paulo, Departamento de Enfermagem da Universidade Federal de Santa Catarina, 1988. p. 63-9. (Resumo)

15. .Fatores de risco numa empresa de eletrificação: uma perspectiva cultural. Florianópolis, 1988. p. 385. Dissertação (Mestrado)Universidade Federal de Santa Catarina.

16. SPRADLEY, J. The ethnographic interview. Forth Worth: Hancourt Brace Jovanovich. College, 1979. 